\title{
REVISIÓN CRÍTICA DE LA HISTORIA DE LA RETÓRICA DESDE LOS POSTULADOS DE LA COMUNICACIÓN
}

\author{
Juan Rey \\ (Universidad de Sevilla) \\ juanrey@us.es
}

\begin{abstract}
Resumen: Este artículo plantea una revisión de la historia de la retórica desde la comunicación. En él se establecen tres grandes apartados. El primero aborda el nacimiento de una nueva técnica de comunicación, su relación con los sofistas y la democracia, y la transformación realizada por Aristóteles. El segundo, su decadencia. En él se estudia el formalismo de Gorgias, el academicismo de Roma, la irrupción del Cristianismo y su prolongada agonía. Y el tercero, su renacimiento. En él se analiza el papel de la nueva retórica de Perelman y su contexto histórico: los regímenes democráticos y la sociedad de consumo. Se concluye con una correlación entre retórica, democracia y relativismo, y la comunicación como denominador común.
\end{abstract}

Palabras claves: Retórica, historia de la retórica, retórica y comunicación, retórica publicitaria, publicidad.

Abstract: This article proposes a review of the history of rhetoric from a communication point of view. It is organized in three large sections. The first one deals with the birth of rhetoric as a new communication technique, its relationship with sophists and democracy, and the transformation made by Aristotle. The second section talks about its decadency; thus, aspects such as Gorgias' formalism, the academicism in Rome, the irruption of Christianity and its prolonged agony are studied. The third section refers to its renaissance. The role of the new rhetoric by Perelman is analyzed, as well as its historical context: the democratic regimes and the society of consumption. The article concludes with a correlation between rhetoric, democracy and relativism, all of them having communication as a common factor.

Key Words: Rhetoric, history of rhetoric, rhetoric and communication, rhetoric of advertising, advertising.

\section{INTRODUCCIÓN}

Tradicionalmente, la historia de la retórica se ha escrito desde una perspectiva literaria. Esto ha determinado que dicha historia presente una impronta casi exclusivamente literaturizante, lo cual, por una parte, ha venido a certificar la excluyente, y a la postre mortal, vinculación de la retórica con las Letras, que le han impedido desarrollarse en ámbitos más apropiados; y, por otra, ha acelerado el proceso de degeneración de la propia retórica al apartarla de sus fines 


\section{Revisión crítica de la historia de la retórica desde los postulados de la comunicación}

primitivos (la comunicación en la polis) y aplicarla a otros más triviales (el ornato en la escritura).

En su origen, la retórica no se relaciona con la palabra hermosa, sino con la palabra eficaz. Su objetivo es resolver problemas, hallar soluciones. Siempre mediante la palabra: adecuada, precisa, convincente, persuasiva. $Y$ sobre este aspecto es sobre el que debe re-escribirse la historia de la retórica. Este planteamiento implica, a su vez, el estudio de las relaciones de la retórica con actividades actuales en cuyo desarrollo desempeña un papel primordial. Así sucede, por ejemplo, con la comunicación, en general, y con la publicidad, en particular.

Este interés por la palabra como herramienta de trabajo, que va desde la Antigüedad griega hasta el presente, convierte la retórica en una "supracultura" que impregna toda la historia de Occidente:

Basta pensar todo lo que ella, inmutable, impasible y casi inmortal, vio nacer, desaparecer, sin conmoverse y sin alterarse: la democracia ateniense, las monarquías egipcias, la República romana, el Imperio romano, las grandes invasiones, el feudalismo, la monarquía, la Revolución. La retórica dirigió regímenes, religiones, civilizaciones. Moribunda después del Renacimiento, tarda tres siglos en morir. Todavía no es seguro que esté muerta. La retórica da acceso a algo que hay que designar como una "supracultura" (Barthes, 1990: 88).

No obstante, este magma retórico no siempre se ha manifestado de idéntica manera. Se asemeja a un guadiana que, atravesando veinticinco siglos, unas veces muestra su esencia y los hombres acuden a la retórica para planificar el debate u organizar la discusión; y otras se muestra esquivo y entonces la retórica es utilizada como mero ornato. Si se quiere restituir a la retórica su verdadero carácter, resulta imprescindible analizar aquellas etapas en las que se ha utilizado como una herramienta de comunicación. Esta es su auténtica razón de ser: el hecho de ser un instrumento de comunicación, una técnica que sirve tanto para transmitir información de manera adecuada como para preparar un debate con el fin de salir triunfante. Fuera de la comunicación, la retórica no tiene sentido, porque nace para resolver problemas de comunicación entre contendientes, porque sirve para estructurar el discurso con el fin de hacerlo más eficaz, y porque su finalidad es lograr una comunicación adecuada, persuasiva.

Y siempre con la palabra como único argumento. Como afirma Roland Barthes, la retórica "ha sido la única práctica (junto con la gramática, nacida después que ella) a través de la cual nuestra sociedad ha reconocido el lenguaje, su soberanía" (1990: 89). Y ha sido esta preocupación por la palabra, por el estudio de la palabra, por el estudio del uso de la palabra, lo que posibilitó el nacimiento de la retórica, primero, y su difusión, después. La retórica se fundamenta en la palabra y la palabra es el mejor instrumento de comunicación del hombre. Por ello, carece de sentido circunscribir la retórica al mundo literario, porque la palabra supera con creces el ámbito estético para adentrarse y desenvolverse en la vida cotidiana.

$Y$ es en el tráfago de esta en el que cobra su verdadero sentido: en sus 
transacciones, intercambios, disputas, disertaciones, anuncios, acuerdos, juicios, reuniones, mítines... En todas estas acciones está presente la retórica. Unas veces, de manera espontánea. Otras, de forma deliberada. $Y$ es que la retórica forma parte de las estrategias comunicativas de la vida. Cuando un aspirante a un puesto laboral asiste a una entrevista de trabajo, cuando un estudiante pide los apuntes de clase a un compañero al que no le une gran amistad, cuando un spot promociona un champú ecológico, cuando un enamorado intenta granjearse el favor de la chica por la que suspira, cuando una jovencita pretende que su madre la deje regresar a casa más tarde de lo habitual, cuando un político solicita el voto de los vecinos de un barrio, cuando un profesor redacta un artículo, todos, en mayor o menor medida, acuden a la retórica para organizar su discurso y lograr su objetivo. Porque la retórica sirve para construir un discurso adecuado y eficaz. $Y$ esto fue lo que descubrieron y sistematizaron los griegos: las técnicas para elaborar discursos en función del destinatario y las circunstancias.

Ahora bien, esta concepción de la retórica no siempre ha imperado. Por ello es necesario revisar su historia y detenerse justo en aquellos periodos en los que es percibida como un instrumento para construir estrategias comunicativas. Siguiendo este criterio, pueden establecerse tres etapas. En un primer momento, cuando la retórica surge, se vincula a los procesos comunicativos; luego sufre una larga y profunda decadencia en la que se desvincula de sus fines primitivos; y por último recupera su carácter comunicacional.

\section{EL NACIMIENTO DE UNA TÉCNICA}

Ya desde el comienzo su denominación resulta problemática, pues la palabra "rhetorica" aparece en griego tardíamente. La primera vez que se tiene constancia de ella es en Gorgias de Platón (453a) y se trata de un adjetivo referido a un "saber hacer", a una técnica. En cambio el vocablo "rhetor" aparece documentado un siglo antes (Díaz Tejera, 1994: 11). Este desfase viene a demostrar que, cuando se le da nombre a una actividad, esta ya viene desarrollándose desde hace tiempo. Por tanto, cuando Platón la incluye en su discurso, se trata de una práctica consolidada.

En cuanto a su origen, fueron los griegos de Siracusa los primeros que sistematizaron las técnicas retóricas. Su nacimiento, como el de otras actividades, está rodeado de leyendas e inconcreciones. Su creación se atribuye a varios autores. Según una tradición, a la que Aristóteles da crédito, su fundador es Empédocles de Agrigento, filósofo con fama de mago. Según otra, la más difundida y aceptada, son Córax y su discípulo Tisias. Es más sensato pensar que el nacimiento de la retórica como actividad no es el fruto de una o varias personas, sino el resultado de un amplio proceso que James Murhpy llama la "conciencia retórica" y que equivale a lo que, en otros ámbitos, se denomina el "espíritu de la época". Según Murphy, en el teatro y en la poesía griegos, existen 


\section{Revisión crítica de la historia de la retórica desde los postulados de la comunicación}

ciencia retórica mucho antes de que se escribieran los textos que iban a ocuparse de la materia [...]. Estas pruebas ponen de manifiesto que entre los griegos se había desarrollado una conciencia retórica cada vez más sofisticada ya en el siglo $\mathrm{V}$ a.C. Solamente quedaba por hacer la codificación de esas pruebas textuales (1988: 11).

Y esto es lo que hacen Córax y Tisias: recopilan codifican y sintetizan unas técnicas que vienen aplicándose desde hace tiempo en las disputas por las tierras expropiadas. Porque lo que es cierto es que el nacimiento de la retórica está relacionado con las expropiaciones llevadas a cabo, a comienzos del siglo $\mathrm{V}$ a.C., por los tiranos Gelón y su sucesor Gerón I y el reparto entre sus adeptos y mercenarios. La posterior insurrección y el derrocamiento de los dictadores propicia la instauración de la democracia. Pero surge un problema: la propiedad de la tierra, pues los antiguos propietarios la reclaman y los nuevos se niegan a devolverla.

En esta época aún no ha surgido la función del abogado y los contendientes se ven obligados a litigar ante los jurados populares. Para ganar su causa, deben ser "elocuentes" y para ello recurren al logógrafo, una suerte de escribano público especializado en redactar informes, defensas y alegatos que el interesado lee ante el tribunal. $Y$ es en este contexto en el que surge el rétor: un nuevo profesional que ofrece tanto al litigante como al logógrafo sus servicios, que consisten en la composición de un discurso persuasivo, capaz de convencer a cualquiera y de proporcionar, por tanto, la consecución del objetivo (Reboul, 1991: 14). Según la tradición, Córax, a partir de experiencias propias y ajenas, crea "un método perfectamente organizado de debate" (Murphy, 1988: 14), un método que, en su momento, resulta indispensable en las actuaciones judiciales sobre la propiedad de la tierra. Su gran aportación es un Arte retórico, publicado junto con Tisias, que es un compendio de pautas prácticas y ejemplos para uso de litigantes.

La novedad de los rétores es doble, ya que afecta tanto a la elaboración del discurso como a su estructuración. En cuanto a la composición, elaboran un sistema que se desarrolla a lo largo de cinco operaciones. Se trata de una forma de trabajar activa, pues cada una de estas operaciones no son "elementos de una estructura sino actos de una articulación progresiva" (Barthes, 1990: 121). Estas operaciones, en un principio, son cuatro ${ }^{3}:$ 1) héuresis o recogida de información sobre el tema a tratar; 2) taxis o selección y jerarquización de dicha información; 3) lexis o redacción del discurso; y 4) hypokrisis o pronunciación del discurso. En cuanto a la organización, establecen que el discurso, para ser eficaz, debe constar de cuatro partes $\left.{ }^{4}: 1\right)$ exordio, en el que, al comienzo, se intenta seducir a los oyentes (captatio benevolentiae) y, después, se enumeran las partes de que

\footnotetext{
${ }^{3}$ Actualmente, las operaciones retóricas son cinco. La memoria fue añadida por los romanos (v. apdo. 3.2). ${ }^{4}$ Las partes del discurso han ido variando a lo largo del tiempo. Los sofistas la fijan en cuatro. Aristóteles respeta esta partición. Y esta será la que se siga en este trabajo, porque es la más aceptada (Albaladejo, 1989: 82; Barthes, 1991: 145; Lausberg, 1983; Mortara Garavelli, 1991: 69; Reboul, 1991: 66). No obstante, determinados autores han llegado establecer hasta siete partes, pero no se trata de partes nuevas, sino de divisiones como la establecida por Quintiliano, que desdobla la tercera parte en confirmatio y refutatio.
} 
se compone el discurso (partitiones); 2) narratio, en la que se exponen sucinta y funcionalmente los hechos relacionados con la causa; 3 ) confirmatio, que se inicia con una definición de la causa (propositio) y se cierra con la exposición de las pruebas y argumentos (argumentatio); y 4) conclusio (o peroratio), en la que se recapitula todo lo anterior y se establece la idea a defender. Pero la novedad no solo reside en la manera de planificar y estructurar el discurso, cuyo funcionamiento y aplicación resultan a veces un tanto simple y mecanicista, sino en su versatilidad y en su capacidad para replantear continuamente la disputa, de reformular de forma incesante la discusión, pues, como se ha indicado, se trata de "un método perfectamente organizado de debate". Esta es la gran aportación de la retórica primitiva, si bien aún queda la reformulación llevada a cabo por Aristóteles.

\subsection{La conciencia retórica}

La retórica es fruto del espíritu de la época, de la "conciencia retórica" de Murhpy. Es hija de una sociedad determinada y en su nacimiento y desarrollo intervienen factores de la más diversa índole: económicos, judiciales, políticos, pedagógicos, filológicos y filosóficos (Mortara Garavelli 1991: 19).

Desde el punto de vista económico, el nacimiento de la retórica está estrechamente vinculado al problema de la propiedad de la tierra. Puede decirse que, si no es la causa principal, es al menos el detonante gracias al cual confluyen las demás causas. Este origen, no científico, no filosófico, es el que hace a Barthes exclamar irónicamente que "resulta curioso comprobar que el arte de la palabra está ligada originariamente a una reivindicación de la propiedad" (Barthes, 1990: 90 ), cuando en la sociedad actual las reflexiones sobre la lengua se desarrollan en los ámbitos filológicos, lingüísticos y filosóficos.

Debido a los litigios por la propiedad de la tierra, se desarrolla una serie de actividades relacionadas todas ellas con las querellas y las disputas y, simultáneamente, surgen nuevas profesiones vinculadas con ellas, especialmente la de los logógrafos. Es cierto que en ese momento se desarrollan ya determinadas prácticas jurídicas, pues Solón, en el tránsito del siglo VII al VI, determina que todo acusado debe defender su propia causa ante los tribunales, lo que supone un notable antecedente del litigante ante el jurado popular reclamando, no su inocencia, sino su propiedad. La retórica viene, pues, a consagrar una práctica jurídica embrionaria en la que saber expresarse es de capital importancia.

Esta manera de actuar se relaciona con una forma específica de entender la sociedad. La consolidación de la retórica como técnica para construir discursos va unida al desarrollo de la polis y la democracia. Las polémicas políticas, la necesidad de ganar el favor de la asamblea para obtener un cargo público, las disputas sobre asuntos de interés general, la confrontación (verbal) para vencer al adversario, todas ellas son prácticas propias de un régimen en el que "la libertad de la palabra se opone al ejercicio autoritario del poder" (Mortara Garavelli, 1991: 
338 Revisión crítica de la historia de la retórica desde los postulados de la comunicación

19). Solo una sociedad entrenada en el ejercicio de la libertad puede favorecer el nacimiento de una técnica para construir discursos. Se trata, en definitiva, de "una sociedad en la que la conducta individual y colectiva se regulaba en gran medida por unos mecanismos en los que los discursos jugaban un papel muy importante" (Berrio, 1983: 11).

Y esta misma sociedad le concede una gran importancia a la educación de sus ciudadanos, con lo que la retórica, que es una manera de reflexionar sobre la lengua, adquiere un enorme protagonismo en la formación de los individuos y muy temprano se introduce en las instituciones académicas, en las que se convierte en el núcleo esencial de lo que hoy sería la enseñanza superior. Al margen de las diferentes corrientes lingüísticas, todas ellas coinciden en que el conocimiento de la lengua es fundamental para conocer la realidad que expresa. Así, pues, la retórica se convierte también en una ciencia cuyo objeto de estudio es la palabra, la palabra eficaz.

En última instancia, hay que relacionar la retórica con la aparición de nuevas corrientes filosóficas (Berrio, 1983: 16). La filosofía presocrática tiene como centro de interés la naturaleza y la mayor parte de sus tratados y observaciones empíricas tratan de explicar la realidad. Sin embargo, a finales del siglo IV a.C. y comienzos del $V$ a.C., hay un cambio de paradigma y el objeto de estudio es la polis $y$, sobre todo, el individuo, que ahora se convierte en el parámetro del mundo y que debe formarse tanto para alcanzar su plenitud como para servir a la sociedad. Esta visión antropocéntrica da origen asimismo a una nueva concepción organizativa: la democracia, en la que el discurso - para llegar al acuerdo o persuadir al adversario- desempeña un papel fundamental.

Estas son, pues, las diferentes causas que conforman la conciencia retórica. Y son asimismo las que determinan que la retórica pueda ser definida desde distintas perspectivas.

\subsection{La retórica y los sofistas}

Protágoras de Ábdera (481-411 a.C.) abre su obra La verdad con la siguiente cita: "El hombre es la medida de todas las cosas". Esta declaración de principios define magistralmente la postura ante la realidad de los sofistas, que no se consideraban ni sabios ni filósofos, sino "profesionales de la inteligencia" o "maestros del pensamiento" (Romilly, 2010: 19). Y también la de los retóricos, pues para entender la retórica hay que ubicarla en el contexto de la sofística sin el cual carece de sentido. La vinculación de los sofistas con la retórica surge con la cuestión de la verdad. Los sofistas parten de la inexistencia de valores y principios absolutos, pues estiman que todos son fruto de convenciones sociales y que estas varían de una época a otra, de una ciudad a otra. En consecuencia, no existen valores objetivos, sino que todo depende de lo que dictamine el hombre. De ahí que frente a la Verdad, establezcan una verdad contextualizada, es decir, una verdad relativa, funcional, doméstica (Berrio, 1983: 20), pues son los 
hombres los que -con sus palabras- determinan lo que es o no es verdad. Es decir, son unos relativistas avant la lettre, ya que entienden que todo depende del contexto, de los interlocutores, de los objetivos... Y si hoy los hombres, de mutuo acuerdo, deciden adherirse a unos valores, mañana, de mutuo acuerdo, pueden adherirse a otros.

Los sofistas son los primeros en comprender el poder del discurso. Piensan que el hombre vive inmerso en un mundo de cosas, hechos y opiniones que solo cobran realidad mediante la palabra -convencional, subjetiva-. No les preocupa "la verdad ni la falsedad, sino la verosimilitud, la probabilidad, la opinión más útil y favorable, a la que inevitablemente se llega mediante la persuasión que el discurso más convincente es capaz de producir" (García Castillo, 1994: 79). Y son los sofistas también los creadores de la retórica como técnica para generar discursos persuasivos y los que la convierten en objeto de estudio y enseñanza sistematizada. A ellos, en definitiva, les debe la retórica los siguientes aspectos (Reboul, 1991: 21): los primeros esbozos de una gramática, la disposición las diferentes partes del discurso, el empleo de una prosa elegante y persuasiva, y el concepto de kairós o la elección del momento oportuno para decir el discurso.

Como corriente filosófica, los sofística se enfrentan a la encabezada por Platón (427-347 a.C.): a un pensamiento centrado en la naturaleza oponen otro focalizado en la polis y, sobre todo, en el individuo y sus problemas; a una concepción aristocrática de la sociedad oponen una concepción democrática; a unos valores absolutos, inmutables e inalterables por el hombre, oponen unos valores relativos, mutables y alterables; a una filosofía elitista oponen una pedagogía democrática5; a lo cierto oponen lo probable; y a lo abstracto (lo sublime) oponen lo concreto (lo diario) (Romilly, 2010: 148). Y todo ello con la palabra como único instrumento, con el debate, con la confrontación, porque para ellos es más importante lo que se cree que es verdad que lo que es verdad. Lo que parece verdad -insistencuenta más que lo que es verdad (Mortara Garavelli, 1991: 18). Y "lo que se cree que es verdad" o "lo que parece que es verdad" son los hombres los que lo establecen con sus acuerdos. De ahí la importancia que adquiere la retórica en el ámbito de los sofistas, pues la única posibilidad que tiene el hombre de expresar algo es mediante el discurso, el discurso bien planificado, bien estructurado, el discurso eficaz, persuasivo. Los sofistas son "maestros de la palabra".

Para los sofistas, la retórica es "el arte de construir el mundo" (García Castillo, 1994: 80), un arte en el sentido latino del término ars, que equivale a la techné griega. Una técnica, que se fundamenta, no en la violencia ni la coacción, sino en el sabio uso de las palabras, pues la polis, terreno natural de la retórica, es el lugar en el que coinciden opiniones diversas, voces contrarias, conceptos encontrados, y todos ellos, gracias al discurso, confluyen en un fin común. Se

\footnotetext{
${ }^{5}$ Una de las razones por las que Platón critica a los sofistas es porque son profesores que van de ciudad en ciudad impartiendo sus conocimientos y además icobran por ello! (Romilly, 2010: 74).
} 


\section{Revisión crítica de la historia de la retórica desde los postulados de la comunicación}

trata del poder transformador de la palabra persuasiva, no de una doctrina falsa en otra verdadera, sino de una postura ineficaz en otra útil, ventajosa y beneficiosa para la ciudad. Esta es, según Protágoras, la auténtica paideia: "el saber más fundamental que es capaz de hacer del hombre un excelente ciudadano, pues solo mediante el arte de la discusión, que respeta las opiniones contrarias como igualmente válidas, puede convertir a los ciudadanos en amigos" (García Castillo, 1994: 79).

Frente al "relativismo pragmático" (Reboul, 1991: 20) que practican los sofistas, Platón es tajante: "Un auténtico arte de la palabra que no esté ligado a la Verdad ni existe ni podrá existir jamás" (Fedro, 260e). ¿De dónde surge la animadversión de Platón hacia los sofistas? Platón no puede desentenderse de la retórica, ya que impregna toda la sociedad griega. Los sofistas han creado un modo de entender la vida y, sobre todo, una forma de considerar y transmitir el conocimiento. Isócrates (436-338 a.C.) convierte la retórica en la base de su plan de estudios, cuyo objetivo es la formación de los estadistas que han de manejar los asuntos públicos. Entiende que un gobernante, además de habilidad natural y experiencia, debe poseer una sólida formación. El conocimiento es, pues, piedra angular para lograr excelentes gobernantes (y ciudadanos) y se les puede transmitir mediante discursos organizados de acuerdo con los postulados de la retórica. El discurso retórico es, pues, una herramienta de transformación del hombre, de educación del ciudadano.

Es en este ambiente dominado por los sofistas (Romilly, 2010: 53) en el que Platón escribe sus diálogos, en varios de los cuales aborda la cuestión retórica. En Protágoras, Eutidemo y Gorgias la critica de manera severa, especialmente en el tercero. Define la retórica como una "práctica rutinaria", una actividad "aduladora y vergonzosa", un "halago mentiroso", un "remedo" de la actividad jurídica, un simple "ejercicio formal" de persuasión que se practica sin tener conocimiento de los temas que trata, un mero truco para seducir y encantar al auditorio con sus hermosas palabras. $Y$ asimismo entiende que tener el poder de transformar la mente de los hombres es peligroso porque puede aprovecharse de la ignorancia del público; que no puede ser considerada una técnica, porque carece de fundamento racional, sino que debe ser entendida como mera adulación, ya que provoca el engaño mediante palabras de agradable apariencia; y que es solo un instrumento como "la cocina", referencia que alude a Gorgias de Leontini (485-380 a.C.), quien afirma que la retórica es igual que la medicina y así como esta sana o envenena con medicamentos, aquella actúa de idéntica manera pero mediante la palabra. Platón la rebaja de la medicina a la cocina, actividades que tienen en común el uso de fármacos y alimentos para tratar a los enfermos, pero entre las que media una gran diferencia (Ritoré Ponce, 1994: 72).

En cambio en Fedro adopta una posición más conciliadora, al distinguir entre la verdadera y la falsa retórica. Es verdadera aquella que, ya sea en los tribunales, en las reuniones o en la vida privada, conduce al alma hacia la verdad: la retórica es entonces "el arte de ganarse -o de encantar- el alma con el discurso". Es 
falsa aquella que hace gala de verdad pero que es solo pura lisonja para obtener el favor del jurado. La primera es la retórica filosófica, la retórica dialéctica. La segunda, la retórica de los retóricos, de los sofistas. E incluso, respecto a la buena retórica, hace algunas propuestas de mejora como que el orador debe conocer el tema sobre el que habla (aspecto sobre el que, por cierto, Gorgias insiste una y otra vez), que la retórica resulta útil en el tratamiento de temas dudosos, y que la eficacia de la retórica depende tanto del conocimiento que el orador tenga de la naturaleza y del alma como de su habilidad para "encantar" el alma (Murphy, 1988: 31). No obstante, la vincula y la somete a la dialéctica, que, a su vez, está al servicio de la verdad. De esta manera, Platón recupera la retórica y, al mismo tiempo, la desvirtúa, pues, en su sistema de valores, la ciencia tiene mayor importancia que la opinión, es decir, "la certidumbre de la verdad [prevalece] sobre la mutabilidad de lo opinable" (Mortara Garavelli, 1991: 22). Exactamente lo opuesto de lo que creen y defienden los sofistas.

No es extraño, pues, que Platón, el triunfador de esta contienda, critique la retórica y la vitupere acremente en sus diálogos. Y tampoco resulta extraño que estas críticas y vituperios hayan pervivido a lo largo de la historia hasta conformar un conglomerado de opiniones (negativas) sobre la retórica entre las que cabe destacar las siguientes:

La retórica no es un arte veraz, sino un conjunto de artificios (de falacias, de formas hueras), y, por ende, un engaño, lo opuesto a la espontaneidad y la sinceridad; la persuasión, que es una manipulación del consenso por parte del que es más astuto y sabe cómo embaucar a los ingenuos, se ejecuta en materia de dudosa consistencia, sobre las que el acuerdo no es general, y usa a menudo trucos de prestidigitador; la multitud es su destinatario natural, mientras que la búsqueda de la verdad y del conocimiento requiere un intercambio dialéctico entre los interlocutores; por ello, la retórica es una actividad estéril desde el punto de vista cognoscitivo (Mortara Garavelli, 1991, 24).

Y son estas las opiniones las que han servido para referirse a la retórica hasta bien entrado el siglo XX. Y las que han contribuido a consolidar su desprestigio.

\subsection{Retórica y democracia}

La retórica solo puede surgir en una sociedad democrática, en la que todos los hombres son iguales, en la que se accede al poder mediante el acuerdo de sus ciudadanos y en la que este se ejerce mediante la palabra. Este tipo de sociedad surge en Grecia hacia el siglo V a.C. (Berrio, 1983: 11). Se trata de una sociedad que funciona gracias a la participación de sus ciudadanos en los diferentes niveles (asambleas populares, tribunales de justicia, etc.), en los que se debate, se argumenta, se discute. Y en esta sociedad la palabra -el discurso bien construido- adquiere una enorme importancia, ya que de ella depende el 
342 Revisión crítica de la historia de la retórica desde los postulados de la comunicación

triunfo de las ideas defendidas, la derrota del adversario.

Tácito, en plena época imperial, plantea en el Diálogo de los oradores la cuestión de las razones de la decadencia de la retórica después de Cicerón (Reboul, 1991: 84). Uno de los protagonistas explica que la retórica se desarrolla en una sociedad "en la que resulta indispensable". Es decir, surge en "una sociedad que la necesita", para decidir, para elegir, para gobernar. $Y$ esta no es otra que la democracia. Antaño, expone, cualquier decisión debía tomarse tras un debate público. En este sentido, el futuro orador se formaba en pleno campo de batalla: la asamblea, el tribunal, el foro, en los que asistía a los debates, escuchaba a los expertos, aprendía las técnicas, observaba la reacción del público y, en última instancia, participaba. En cambio hoy, se lamenta, los muchachos aprenden en la escuela, de forma ficticia, sin más público que sus compañeros, tan inexpertos como ellos, y tratan, no sobre temas reales, sino absurdos, irreales. Antaño es la República y hoy es el Imperio.

El esplendor de la retórica coincide, pues, con los momentos de democracia: las ciudades-estado de Grecia y la República de Roma. Y si en Grecia, una vez abolida la polis y perdidas las libertades cívicas, la retórica se convierte en "un ejercicio intrascendente", en Roma, una vez instaurado el Imperio, la retórica "se retira a las escuelas" en las que se practica como "arte teatral y declamatoria" (Spang, 2006: 47 y 50). En ambos casos, por razones políticas, deja de ser una actividad "necesaria" para convertirse en una simple actividad académica. Una vez invadida Roma, se sucederán imperios sanguinarios, teocracias oscurantistas, monarquías absolutas y regímenes dictatoriales, y habrá que esperar casi dos mil años para que la retórica encuentre de nuevo el terreno propicio.

\subsection{Los primeros avatares}

El mismo año que nace Platón (427 a.C.), Gorgias, alumno de Empédocles de Agrigento y gran sofista, viaja de Siracusa a Atenas en calidad de embajador. Tras sus gestiones se queda en la ciudad ática y abre una academia para enseñar la técnica del discurso. Con él, la retórica se traslada de Sicilia a Atenas, en la que se perfecciona y desarrolla. De su importancia para la historia de la retórica cabe destacar sus postulados sobre el lenguaje, la defensa del poder mágico de la palabra y su interés por crear un discurso bello, tema este que será tratado en el apartado siguiente.

Su punto de partida es el supuesto epistemológico según el cual todo conocimiento depende del sujeto. Su idea central es la relatividad y mutabilidad del sujeto, cuyo conocimiento se desenvuelve en circunstancias y situaciones diferentes, por tanto -establece- es imposible hallar la más mínima posibilidad de encontrar un criterio de verdad. Su posición es más radical aún que la de Protágoras. Si este entiende que el hombre es el parámetro de todo, incluida la verdad, aquel determina que no hay ningún discurso que pueda representar la verdad (Román, 1994: 43). Lo único que se puede conocer es lo que se percibe y la percepción 
depende de los sentidos. Lo que el hombre denomina realidad está constituido, pues, por lo percibido. La palabra se genera a partir de lo percibido, pero entre la palabra y la realidad media un abismo. Ante esta tesitura afirma que no hay traducción posible de la realidad mediante la palabra (1994: 41). Lo único que le queda al hombre es la palabra, el discurso. La retórica se convierte entonces en el centro de atención de Gorgias.

Esta retórica, que aún está en sus comienzos, algunos la relación con la medicina y la magia, con las que tiene en común -afirman- determinados efectos persuasivos y salutíferos. Se trata de la retórica psicagógica, o "conductora de almas", según la cual el poder de la retórica no radica tanto en la planificación y estructuración del discurso como en la fascinación poética de la palabra que, "sabiamente manipulada" puede ejercer su influencia sobre los oyentes. Su objetivo no es la adhesión racional del auditorio, sino su reacción emotiva. Gorgias es uno de los principales promotores y defensores del poder mágico de la palabra. Y también de los primeros en relacionar el lenguaje (elocuencia) y la técnica (persuasión). De la síntesis de ambas surge la retórica cuya finalidad es producir ciertos efectos en el alma del oyente. Así puede leerse en su Elogio de Helena, en el que equipara la retórica a la medicina:

El poder del discurso sobre la constitución del alma puede ser comparado al efecto de las drogas sobre el estado corporal. Así como estas, al expulsar los diferentes humores del organismo, consiguen poner fin a la enfermedad o a la vida; lo mismo ocurre con el discurso: palabras diferentes son capaces de despertar dolor, placer o temor, o también -a través de una persuasión dañina- llegar a narcotizar y hechizar el alma.

Uno de los aspectos más interesantes que desarrolla la retórica psicagógica en relación con la retórica posterior (y especialmente con la comunicación moderna) es el concepto de politropía, es decir, la capacidad que debe tener el orador para crear discursos distintos según el receptor. Este concepto está vinculado con la medicina. Y así como el médico busca y aplica los remedios según las dolencias del paciente, del mismo modo el orador debe construir un discurso acorde con el oyente. Aristóteles hablará continuamente del auditorio, al que se debe adecuar siempre el discurso. Y la publicidad moderna, de público objetivo, al que debe adecuarse el mensaje; y las cadenas de televisión, de audiencia, a la que debe adecuarse la programación.

Isócrates es, junto a Gorgias, uno de los grandes precursores de la retórica. Como filósofo, su interés se centra en la formación de los futuros administradores de los asuntos públicos, a los que debe proporcionárseles una excelente educación, pues de ella depende el buen gobierno. Y el mejor método para transmitirles el conocimiento necesario es mediante el recurso a unos discursos planificados y estructurados según los principios de la retórica. Como Gorgias, le concede gran importancia a la forma del discurso y se esfuerza por crear un estilo de prosa artístico, pero evita y critica sus los excesos. Si Gorgias se centra en la emoción, Isócrates en la razón. Si el objetivo de aquel es persuadir, el de este 


\section{Revisión crítica de la historia de la retórica desde los postulados de la comunicación}

es educar. Si aquel somete el discurso a la forma hasta deformarlo, este entiende que la forma es un medio para transferir conocimientos. Entre sus aportaciones a la conformación de la retórica cabe destacar las siguientes: la retórica es una técnica, no una ciencia; tanto el discurso como sus partes deben acomodarse a las circunstancias; una buena voz es fundamental para triunfar en la oratoria; los discursos no pueden aprenderse de manera mecánica, sino que deben ejercitarse y practicarse como una técnica; no solo deben estudiarse los buenos discursos, sino todos, porque de todos se aprende; y el discurso debe prestar atención a la justicia y la virtud (Murphy, 1988: 27).

\subsection{La revolución aristotélica}

Desde la perspectiva retórica, Aristóteles, discípulo de Platón, es el punto de llegada y también el de partida. Aristóteles cierra una etapa y, simultáneamente, abre otra. Sin la herencia sofista, de cuyos postulados es un excelente conocedor, no hubiera podido elaborar sus teorías, pero, sin su reelaboración, la retórica no sería lo que es en la actualidad. La retórica aristotélica representa, pues, la superación del enfrentamiento entre sofistas y platónicos, al tiempo que es una síntesis, reestructuración y reformulación de todos sus principios.

\subsubsection{La herencia recibida}

La herencia retórica de Aristóteles es doble (Díaz Tejera, 1994: 1). De una parte, le llega una "retórica artificiosa", cuyo más genuino representante es Gorgias. Se trata de una retórica en la que la única verdad posible reside en la misma palabra, una retórica vinculada a la medicina y cuyo objetivo es la persuasión. Una retórica, en definitiva, "ya hecha", que sirve de modelo y que solo permite la repetición, la imitación. El eco de esta retórica primitiva pervive en dos aspectos fundamentales de la retórica aristotélica: ningún conocimiento se asienta sobre valores absolutos (Gorgias) y la retórica sirve para instruir al pueblo (Isócrates). Y de otra, le llega una "retórica práctica real" constituida por la gran oratoria griega cuyo máximo exponente es Demóstenes. Se trata de una retórica que se ejercita a diario en las asambleas y los tribunales, y que se preocupa de determinados aspectos como las circunstancias del discurso, el auditorio, el tono de voz o la melodía de la frase. Una retórica, en resumen, que no es un modelo a imitar sino una realización concreta, específica, ejecutada de acuerdo con unas coordenadas espacio-temporales determinadas. Esta retórica es una técnica, pero también, y sobre todo, es una facultad: "La retórica es la facultad de teorizar lo que es adecuado en cada caso para convencer" (I 2, 1356a).

Aristóteles hereda, pues, un enorme bagaje retórico que, además de los referidos en el párrafo anterior, incluye aspectos básicos como las nociones de verosimilitud, opinión, adecuación o persuasión; las diversas reacciones anímicas que el hablante, con su discurso, despierta en el oyente; el conocimiento que el 
orador debe tener sobre las cuestiones que trata; los diversos tipos de razonamiento; y el método dialéctico. No obstante su novedad radica "en haberlos proyectado y jerarquizado en una estructura filosófica global” (Díaz Tejera, 1994: 4). Heredero de una rica tradición, retoma todos los aspectos -sueltos, aislados- de la retórica anterior y los analiza desde una perspectiva común que los aglutina y les da sentido: la comunicación. Esta concepción queda reflejada en su Retórica, que se compone de tres libros, de los cuales el primero habla del orador -el hablante- y de la concepción de los argumentos de acuerdo con el receptor; el segundo, del auditorio -el oyente- y de las emociones que debe despertársele para conseguir su predisposición favorable; y el tercero, del asunto -el mensaje-, de su ordenación y elocución. Ahora la finalidad de la retórica no es persuadir ni educar, sino proporcionar al oyente los criterios suficientes para que pueda tomar "una decisión razonable" (Díaz Tejera, 1994: 6). Esta visión tripartita del hecho retórico le da pie para establecer tres tipos de discurso: judicial, deliberativo y epidíctico, que no son fruto de la artificiosidad retórica sino de la experiencia cotidiana de los hombres.

La concepción que tiene Aristóteles de la retórica es novedosa y aglutinadora. Es novedosa porque supera el marco al que tradicionalmente queda circunscrita: la persuasión. No le niega la función persuasiva. Simplemente, a diferencia de los sofistas, la reduce a su justo término y, sobre todo, la racionaliza al dotarla de argumentos, ya que entiende que "la persuasión es una especie de demostración" (I 1, 1354b). De ahí que hable en ocasiones de "argumentos de persuasión": "Su tarea [de la retórica] no consiste en persuadir, sino en reconocer los medios de convicción más pertinentes a cada caso" ( $1,1355 b)$. Y es aglutinadora porque toma todos sus elementos y no los analiza por separado, sino que los ubica bajo el paraguas de la comunicación. Puede decirse que la Retórica aristotélica es el primer tratado de comunicación de Occidente (Rey, 2003: 440). Para Aristóteles la retórica constituye un triple saber: creativo, práctico y teórico. Creativo porque, a diferencia de la "retórica recetaria" heredada, la suya es dinámica, es decir, la suya es una facultad que le permite al orador, no repetir un discurso ajeno, sino crear el suyo propio de acuerdo con las necesidades del momento. Práctico porque su objeto de estudio no es abstracto, como el de la ciencia, sino que se puede aplicar a casos concretos y, por tanto, tiene una enorme utilidad en la vida diaria. Y teórico porque permite la reflexión sobre sus propios principios. Como puede observarse, la impronta de Aristóteles en la retórica es de enorme importancia y dejó una huella que ha llegado hasta el siglo XXI. Entre sus aportaciones cabe destacar (Murphy, 1988: 106): la clasificación de los tres discursos, la lista de tópicos, la separación entre la prueba y el argumento, el carácter del orador y la relación de virtudes y vicios del estilo.

\subsubsection{Retórica versus poética}

Si hay un rasgo que diferencia la retórica de Aristóteles de la prearistotélica (e incluso de la posaristotélica) es la separación que establece entre retórica y 


\section{Revisión crítica de la historia de la retórica desde los postulados de la comunicación}

la poética. Aristóteles le concede gran importancia a la forma. De ahí que se preocupe de identificar y catalogar los vicios y virtudes del estilo. Pero no cae en los excesos de Gorgias. Para él, el estilo se fundamenta básicamente en la claridad y la propiedad (Murphy, 1988: 93). Si el lenguaje no es claro, no puede cumplir su cometido; y si no es apropiado, no puede convencer. Entiende que se trata de dos técnicas distintas, autónomas. $Y$ a cada una le dedica un tratado: la Retórica, que trata del "acto de la comunicación cotidiana", y la Poética, que versa sobre "el arte de la evocación imaginaria" (Barthes, 1990: 93). Y es justo esta oposición retórica/poética lo que diferencia su retórica de las demás.

La retórica aristotélica se interesa por el razonamiento, es un método deductivo. En ella, los aspectos ornamentales del discurso ocupan un lugar muy secundario. En la etapa anterior, en cambio, la retórica está fuertemente vinculada a la poesía. Recuérdese los intentos de Gorgias de crear una prosa poética bajo cuyos efectos pudiera "guiar el alma" del oyente. Y después de Aristóteles sucede lo mismo. La retórica deja de identificarse con los problemas de pruebas y argumentos y se centra en la composición y el estilo. Así ocurrirá en la Edad Media, en la que las "artes retóricas" son las "artes poéticas". Y esta identificación -antiaristotélica- es el origen, por una parte, de la Literatura y, por otra, de la decadencia de la retórica como luego se verá. La retórica verdaderamente aristotélica, entendiendo por tal la que se preocupa de los razonamientos y la que nada tiene que ver con los aspectos poéticos del lenguaje, puede observarse en la teoría del propio Aristóteles, en la práctica de Cicerón y en la pedagogía de Quintiliano (Barthes, 1990: 94). Todo lo demás es Literatura.

\subsubsection{Retórica y dialéctica}

Otro rasgo que caracteriza a la retórica aristotélica es su vinculación con la dialéctica. Si, por un lado, Aristóteles, a diferencia de los sofistas, distancia la retórica de la poética; por otro, contra los postulados de Platón, la vincula con la dialéctica. El origen de la dialéctica se remonta a las controversias de los sofistas, una especie de lucha entre dos adversarios que, ante el público, defienden tesis opuestas. Esta confrontación tiene la clásica aura deportiva de los griegos: dos sujetos se enfrentan mediante la palabra y uno de ellos debe resultar vencedor. Platón, siguiendo los pasos de su maestro Sócrates, hace de ella un método de la filosofía y la pone al servicio de la verdad. Para él, la dialéctica, asociada a la filosofía, es todo lo contrario de la retórica, a la que considera una mera actividad rutinaria y halagüeña. Aristóteles, por el contrario, estima que la dialéctica es una técnica para regular los diálogos (Reboul, 1991: 39). Lo que, según él, la distingue de la demostración científica y filosófica es que, a diferencia de estas, razona a partir de lo probable; y lo que la distingue de la controversia sofista es que se trata de un método riguroso de razonamiento que se desarrolla respetando estrictamente las leyes de la lógica.

Para Aristóteles es evidente que retórica y dialéctica se relacionan estrecha- 
mente. Así lo expresa en dos ocasiones en su Retórica. En la primera línea afirma de su tratado: "La retórica es una antístrofa de la dialéctica, ya que ambas tratan de aquellas cuestiones que permiten tener conocimientos en cierto modo comunes a todos y que no pertenecen a ninguna ciencia determinada" (I 1, 1354a). El término antístrofa, expresión de origen teatral y además usado metafóricamente, es de muy difícil traducción. Su significado es que la retórica es como la dialéctica: un saber de orden lógico-formal, lo que, además, la independiza de la ética. Con esta primera afirmación, Aristóteles zanja de golpe las objeciones que Platón le hiciera a la retórica en Gorgias y, al mismo tiempo, establece que la relación entre ellas es de identidad y oposición (Racionero, 1999: 161). De identidad, porque las dos versan sobre la misma materia ("ambas tratan de aquellas cuestiones que permiten tener conocimientos comunes a todos") y de oposición, porque cada una trata esa materia de forma distinta.

Un sentido similar expresa cuando, más adelante, afirma que "acontece a la retórica ser como un esqueje de la dialéctica y de aquel saber práctico sobre los caracteres al que es justo denominar política" (I 2, 1356a). La idea expresada con el término "esqueje" es similar a la formulada con "antistrofa", ya que en el esqueje, metáfora tomada de las ciencias naturales, se da, respecto a la planta matriz, una relación de identidad y, al mismo tiempo, de independencia. Aristóteles es taxativo a la hora de establecer la relación entre una y otra: la retórica "es, sin duda, una parte de la dialéctica y su semejante [la política]" (I 2, 1356a). Asimismo es contundente cuando establece la naturaleza (común) de ambas: "ni una ni otra constituyen ciencias acerca de cómo es algo determinado, sino simples facultades de proporcionar razones" (I 2, 1356a). Ambas se ocupan de los enunciados probables. Esta definición es sumamente importante para la historia de la retórica, porque establece la estrecha relación existente entre ella y los saberes de la filosofía práctica: la dialéctica y la política (Racionero, 1999: 178). La vinculación entre una y otra sirve para instituir la diferencia -junto con la separación de la poética- entre la retórica aristotélica y las demás. Pero también servirá para marcar, una vez rota la relación, el proceso de desvirtuación que conducirá a la retórica hasta su casi desaparición.

Según Aristóteles, la retórica es una disciplina que se ocupa de la confrontación de los discursos. Su objetivo es persuadir al adversario con el fin de modificar su conducta. La dialéctica, en tanto que "disciplina filosófica y específicamente lógica dedicada a la argumentación como método de construir razonamientos" (Albaladalejo, 1989: 13), tiene idéntica finalidad. En este sentido, las dos son técnicas instrumentales para generar argumentos $\mathrm{y}$, por tanto, tiene en común una serie de aspectos (Reboul, 1991: 4). Ambas pueden probar una tesis y la contraria, lo que no indica que las dos tesis sean equivalentes (afirmarlo sería caer el error de los sofistas). Ambas son universales en el sentido de que no son ciencias específicas sino técnicas para discutir acerca de todo lo posible. Ambas, como técnicas que son, pueden ser enseñadas. Ambas, a diferencia de la sofística, son capaces de distinguir lo verdadero de lo aparente: la dialéctica, el silogismo del sofismo y la retórica, lo persuasivo de lo engañoso. Y ambas utilizan los mismos 
348 Revisión crítica de la historia de la retórica desde los postulados de la comunicación

tipos de argumentación: la inducción y la deducción, que se encuentran a medio camino entre la demostración de la ciencia y la controversia de la sofística.

Pero también hay diferencias entre ellas (Reboul, 1991: 47-53). En cuanto a la relación entre ambas, la retórica es una de las posibles aplicaciones de la dialéctica: una aplicación concreta, social. Por su parte, la retórica utiliza la dialéctica para convencer, es decir, la usa como instrumento intelectual para persuadir. De este modo, la dialéctica se convierte en la parte argumentativa de retórica. $Y$ en cuanto a su campo de acción, la dialéctica es un juego especulativo, un juego intelectual cuya moralidad radica en el estricto respecto a las normas que la rigen. Por el contrario, la retórica no es un juego, es una herramienta de acción social y su territorio es el de la deliberación. A diferencia de lo que sucede en la dialéctica, en la retórica no se trata de mantener una tesis, sino de defender una causa. La retórica abandona el mundo de las ideas para ocuparse de situaciones específicas. La retórica no juega con las ideas, porque lo que está en juego es el destino jurídico, político o ético de los hombres. La retórica está vinculada a la vida cotidiana y su cometido es ayudar a tomar decisiones razonables en asuntos que afectan a los hombres: declarar o no la guerra, condenar o no a un individuo... La dialéctica es una disciplina lúdica. En cambio, la retórica es una disciplina útil, porque contribuye a dilucidar los conflictos e incertidumbres en los que está inmerso el hombre. Aristóteles distingue dos mundos. Por una parte está el mundo divino ("cielo"), que acoge tanto a lo invisible (Dios) como lo visible (astros). Y por debajo, el mundo terrenal ("sublunar"), dominado por la contingencia, lo previsible, el azar; un mundo en el que existe lo verosímil, lo probable, y en el que es impensable la existencia de una "ciencia perfecta" como la astronomía matemática, que rige el movimiento de los astros; un mundo abierto y sujeto a la acción humana. Este es el mundo de los hombres, un mundo en el que nada está resuelto de antemano, un mundo sometido al ciego azar, en el que las decisiones pueden ser más o menos justas; las previsiones, más o menos probables; las pruebas, más o menos convincentes; las opciones, más o menos razonables. Este es el mundo de la retórica.

\section{DECADENCIA Y CASI MUERTE}

Tras Aristóteles, la historia de la retórica se reduce a una paulatina e inexorable decadencia. Como afirma Reboul, "la historia de la retórica se acaba con sus comienzos" (1991: 14). Es decir, su historia, aunque densa y fructífera, es breve: la etapa griega; el resto es una dilatada degeneración. Así como las causas de su nacimiento son múltiples y heterogéneas, las razones de su declive son igualmente numerosas y variadas; y en la base de todas ellas está la desaparición de su carácter instrumental tanto en el terreno de la comunicación como de las relaciones sociales. Y así como surge tras un largo proceso de conformación, modificaciones y reajustes, del mismo modo va degenerando durante un largo periodo de dos mil años hasta quedar transformada en un remedo de sí misma 
y convertida en sinónimo de mentira, engaño, palabrería.

\subsection{El germen del ocaso}

Ya desde su nacimiento, la retórica es portadora de la semilla de su decadencia: la pasión por el adorno, que, a la postre, será la principal causa de su eclipse. Los griegos identifican la literatura con la poesía, ya épica, ya trágica, $y$, en cambio, la prosa tiene un carácter funcional cuyo cometido es transcribir la lengua oral. Gorgias cree que ciertos rasgos estilísticos hacen que la prosa, empleada en la retórica, sea más persuasiva. Por ello, se esfuerza por utilizar esquemas fónicos y sintácticos con la intención de provocar determinadas reacciones en los oyentes. El resultado de este empeño es una prosa elocuente, en ocasiones demasiado artificiosa. El papel histórico de Gorgias consiste en haber ubicado la prosa bajo el código retórico, al tiempo que la acredita como discurso culto. En cierto modo, Gorgias es el creador del discurso epidíctico, un discurso elogioso que recurre al empleo de figuras, cuyo abuso da lugar a una "prosa decorativa", una "prosa espectáculo". Al insistir en el empleo de las figuras, siempre con fines persuasivos, Gorgias "abre la prosa a la retórica y la retórica a la estilística" (Barthes, 1990: 91). Y termina estableciendo una relación entre la retórica y la belleza que, en el futuro, actuará como elemento desvirtuador.

\subsection{Roma: de la República al Imperio}

La retórica posaristotélica, una vez estructurada y pulida, desembarca en la Roma republicana a mediados del siglo II a.C. Con la caída de la República y el advenimiento del Imperio, la retórica pierde su razón de ser, pues la sociedad que la sostiene, es decir, la sociedad que, según Tácito, la necesita, desaparece y, en su lugar, surge otra nueva, distinta, cuyas condiciones son contrarias al ejercicio de la oratoria. El carácter dinámico y participativo que caracterizó el nacimiento de la sociedad griega (las ciudades-estado) y los comienzos de la romana (la República), se desvanecen. La instauración del Imperio es una de las razones de la decadencia de la retórica, pues, por razones políticas, se ve forzada a abandonar su compromiso político, civil y social, y se refugia en la escuela. La retórica, de ser una técnica de práctica diaria y utilidad social, se convierte en un mero ejercicio académico.

Surge ahora la Segunda Sofística. Con este término se denomina el periodo comprendido entre la llegada de Tiberio al poder (14 d.C.) y la caída de Roma (410 d.C.). En este clima autocrático, el discurso deliberativo queda casi proscrito y el judicial resulta cada vez más comprometedor. Solo el epidíctico goza de cierta permisividad. Una vez suprimidas las libertades, la retórica, privada de todo compromiso social, se transforma en una mera actividad académica. Cada vez importa menos el tema tratado y más el estilo. De ahí que la enseñanza de la retórica incluya un estudio pormenorizado de las figuras. La consecuencia es 
350 Revisión crítica de la historia de la retórica desde los postulados de la comunicación

un ejercicio deslumbrante, un discurso huero, vacío.

En este contexto, la retórica sobrevive de forma ficticia: en la declamatio, ejercicio escolar consistente en la improvisación de un discurso (composición y recitación) sobre un tema. Pero este discurso, al carecer ya de finalidad persuasiva y convertirse en algo decorativo, "se atomiza en una cansina serie de pasajes brillantes, yuxtapuestos con un orden rapsódico" (Barthes, 1990: 101). La declamatio, organizada en suasoria (primer ejercicio y más simple, sobre el género deliberativo) y controversia (segundo ejercicio y más complejo, sobre el género judicial), es la prueba más importante que debe superar el estudiante en el sistema de enseñanza latino. Como apunta Murphy, "resulta irónico que la decadencia de la oratoria romana [...] tuviera lugar al mismo tiempo que se convertía en la disciplina más importante de la educación romana" (1988: 213).

En conjunto, Roma no hace aportaciones significativas en el campo de la retórica ni produce grandes obras. Aunque la retórica es creada por los griegos, "fue la actividad teorizadora de los romanos, con su espíritu práctico, la que produjo una sistematización retórica sumamente coherente y sólida" (Albaladalejo, 1989: 29). La importancia de Roma radica, pues, en la labor de recopilación y sistematización de los conocimientos retóricos. En este sentido, su elocuencia es "una reelaboración de la retórica griega y, en concreto, de las teorías aristotélicas y posaristotélicas" (Mortara Garavelli, 1991: 37). No obstante, muchos críticos están de acuerdo en que la Rhetorica ad Herennium representa la mayor aportación de Roma a la retórica. Se trata de una obra aparecida en torno al año 85 a.C. y que durante muchos años se creyó que era de Cicerón, pero que hoy, con sólidos argumentos, se ha atribuido al rétor Cornificio. La obra es un manual, muy técnico, en el que, de una parte, se insiste en el valor de las figuras y, de otra, en el compromiso moral y civil de los oradores. Su importancia reside en dos aspectos (Mortara Garavelli, 1991: 38). Primero, porque, mediante una rigurosa traducción del griego, crea la nomenclatura retórica latina. Así, en el caso de las operaciones, la héuresis pasa a denominarse inventio; la taxis, dispositio; la lexis, elocutio; y la hypokrisis, actio o pronunciatio. Y segundo, porque incorpora una nueva operación: la memoria, previa a la actio. De este modo, las operaciones retóricas pasan a ser cinco, que es como se las conoce en la actualidad.

\subsection{La irrupción del Cristianismo}

El Cristianismo irrumpe en el mundo romano como una "reacción contracultural" (Alberte, 1994: 137). Plantea un rechazo total de la religión, la cultura y la educación romanas. Y la retórica, que forma parte del sistema educativo, se incluye en dicho rechazo. Aunque también es refutada por otros motivos. La postura de la Iglesia primitiva, una vez convertida en religión oficial del Imperio ${ }^{6}$, puede

\footnotetext{
${ }^{6}$ La religión romana fue abolida oficialmente por Teodorico en 392.)
} 
observarse en la pregunta que se formula el apologista Tertuliano en el tránsito del sigo II al III: “¿Qué tiene que ver Atenas con Jerusalén?”. Y a partir de esta cuestión surgen las siguientes dicotomías: el pescador / el sofista, la Iglesia / la Academia y el estilo simplex / estilo eloquens. La idea de los primeros cristianos es que Cristo eligió a un pescador para fundar su Iglesia, no un filósofo, y, por tanto, su manera de hablar debe ser simple, sin adornos. En realidad, la cuestión que subyace es análoga a la planteada entre los sofistas y los platónicos. Estos defendían la existencia de valores universales, absolutos, intocables por el hombre. Los sofistas, en cambio, creían en la existencia de valores relativos, domésticos, acordados por los hombres. Ahora, en el siglo IV, la situación es similar, pues la palabra del dios de la nueva religión es incuestionable. Por tanto, todo debate queda fuera de lugar. Frente a lo probable y lo verosímil, los cristianos propugnan lo absoluto y la verdad. No hay espacio para la discusión, para el acuerdo, pues todo viene dado. El hombre ha sido sometido al nuevo dios. ¿Qué sentido tiene la retórica en esta sociedad?

Si de una parte, la palabra divina es indiscutible; de otra, es persuasiva por sí sola. La cuestión ahora radica en la fuerza de la palabra del nuevo dios, que no necesita artificios ni engaños para convencer a los no creyentes. En los primeros años del Cristianismo son frecuente aseveraciones como las siguientes: "Mi palabra y mi predicación no se apoyan en los discursos persuasivos de la sabiduría humana, sino en la manifestación del Espíritu" (Pablo de Taso); "Nuestro escritores no pierden el tiempo en pulir los párrafos, porque la escuela de Dios no conoce las leyes del encomio ni se entrega a vacuidades sofísticas" (Basilio de Cesarea); o "La Verdad es impermeable a los maravillosos artificios de un ingenio pervertido" (Hilario de Poitiers). No se trata de afirmaciones aisladas, sino de manifestaciones de un sentir general que impregna y condiciona la conducta de los responsables de la nueva religión que ven en la retórica -y sobre todo en la instrucción retórica- el pecado de una cultura mundana que aparta a los hombres de la Verdad. Por ello, los más radicales sostienen que hay que eliminar la retórica de raíz, porque la palabra divina no necesita artificios retóricos, ya que se impone por sí misma, porque está inspirada por el Espíritu y, por tanto, es portadora de la Verdad.

En este enconado debate durante el siglo IV, se produce lo que ha dado en llamarse "el dilema del eclesiástico cultivado". Muchos responsables de la nueva religión fueron educados en el sistema romano y gozan de una excelente formación retórica. Es el caso de los padres de la Iglesia Ambrosio y Basilio que, habiendo sido profesores de retórica, se ven en la tesitura de defender la Biblia, que está escrita en "idioma bárbaro", sin cuidado alguno. Algunos de estos antiguos profesores se preguntan si la educación recibida no es un serio impedimento para ocupar un lugar en el nuevo orden. El caso más paradigmático es el de Agustín de Hipona (+430), que defiende el empleo de la retórica. Su modelo es la oratoria ciceroniana y estima que es de suma utilidad para la Iglesia, ya que puede ser utilizada en una doble dirección: como teoría literaria para interpretar los textos bíblicos y como técnica para formar a los nuevos predicadores (Alberte, 1994: 
352 Revisión crítica de la historia de la retórica desde los postulados de la comunicación

139), entre los que hay que incluir a los apologistas. Para él no cabe la menor duda acerca de la incidencia de la gracia divina a la hora de predicar, pero al mismo tiempo es consciente de que el predicador debe estar bien formado. De ahí que entienda que la retórica, como disciplina académica, puede servir para este cometido.

Cuando concluye el enfrentamiento entre antirretóricos y prorretóricos, la retórica ya está tocada de muerte. Si al caer la República, la retórica, privada de todo compromiso cívico y social, se había refugiado en las escuelas y se había convertido en un ejercicio formal, ahora, en una sociedad ajena a sus postulados y dominada por la Iglesia triunfante, se alberga en los púlpitos, desde donde se emite un único y antirretórico discurso: el sermo humilis (Mortara Garavelli, 1991: 43), una homilía en estilo simple para adoctrinar al pueblo. Este sermón, desde el punto de vista de la comunicación, es antirretórico, por varias razones: porque carece de configuración retórica; porque vehicula una Verdad irrefutable; porque el discurso se impone, no por la eficacia de la palabra, sino por su carácter divino; y porque el resultado, no es un acuerdo que conduce a la modificación de una situación previa, sino la confirmación de la existente . Al margen del uso que, en determinados casos, hacen de la retórica los apologistas para combatir a los múltiples enemigos de la Verdad (maniqueos, donatistas, priscilianos, etc.), la retórica aristotélica prácticamente desaparece, porque ya no existe la sociedad que la necesita.

\subsection{Los últimos avatares}

A partir de este momento, y durante más de mil años, desde el comienzo de la Edad Media hasta el siglo XX, la retórica -o lo que queda de ella- sufre un largo proceso que, acentuando el declive, la transforman hasta dejarla, en palabras de Barthes, no muerta pero sí "moribunda" (1990: 114). Este proceso se manifiesta de diferentes formas: diversificación, escriturización, reparto y rechazo.

El primer proceso de transformación (diversificación) lo sufre la retórica en la Edad Media. Tras el ocaso de la cultura romana, las obras retóricas que aparecen en los antiguos territorios del Imperio son simples adaptaciones de viejos tratados. Pero se trata de adaptaciones muy selectivas. Los nuevos tratados (todos ellos preceptivos), no toman la totalidad del corpus retórico clásico, sino aquellos aspectos que sirven para su interés específico. En este sentido, los redactores de cartas seleccionan ciertos aspectos de determinadas doctrinas, los profesores de poesía actúan de idéntica manera y de igual modo se comportan los clérigos. $\mathrm{Y}$ este comportamiento saqueador da lugar a las tres ramas de la retórica medieval: Ars dictaminis, que abarca el género epistolar; Ars poetriae que afecta a la versificación; y Ars praedicandi, que versa sobre los sermones . Las dos primeras surgen en el siglo XII; la tercera, en el XIII. Esta forma de operar, fragmentada, inconexa, da lugar a la un planteamiento "diversificado" de la retórica (Murphy, 1986: 99). A diferencia del carácter unitario que presentaba en la época 
grecorromana, la retórica medieval, debido a este expolio selectivo, presenta un aspecto "disgregado" (Mortara Garavelli, 1991: 29), heterogéneo, diverso.

También durante la Edad Media tiene lugar el segundo proceso (escriturización). La retórica originariamente está pensada para el discurso oral. El discurso se componía y se memorizaba con vistas a su pronunciación, ya en la asamblea, ya en el foro. El final del discurso retórico era su emisión en público. Cuando, tras la instauración del Imperio en Roma, los debates públicos se transformaron en declamatio escolar, la emisión del discurso era ya una manifestación (menor) de la escritura, una exhibición académica en la que la elocutio alcanzaba un protagonismo similar o superior a la inventio y la dispositio. A medida que la retórica se va centrando en la composición y redacción de discurso, es decir, en los aspectos escritos, la memoria y la pronunciatio van perdiendo importancia. Esta pérdida hay que relacionarla con su naturaleza. Mientras que la inventio, la dispositio y la elocutio afectan a la construcción del discurso; la memoria y la pronunciatio, por el contrario, se relacionan con su emisión (Albaladejo, 1989: 58). De ahí que se les otorgue un carácter complementario, es decir, no son consideradas operaciones con un rango similar a las otras tres debido a que no intervienen en la generación del discurso. La importancia adquirida por el ars dictaminis o género epistolar (equivalente a la burocracia actual), de una parte, y la preponderancia que va alcanzando la literatura (ars poetriae) en escrita en las lenguas vernáculas, de otra, todo ello contribuye a focalizar la atención de la retórica en la comunicación escrita, en menoscabo de la oral.

El tercer proceso (reparto) es el resultado de la trayectoria medieval de la retórica y sucede en el Renacimiento. El sistema educativo de la Edad Media, heredero en cierto modo del romano, se organiza en dos apartados: el Quatrivium, que incluye las (cuatro) materias relacionadas con la naturaleza (música, aritmética, geometría y astronomía), y el Trivium, las (tres) relacionadas con la palabra (gramática, dialéctica y retórica). En relación con la evolución de la retórica resulta interesante observar las correlaciones existentes entre las materias integrantes del Trivium. Lo más destacable es que la retórica, al ser "la hermana pobre", muy pronto se ve "arrinconada" por las dos hermanas mayores (Barthes, 1991: 105), porque su función es verba colorat, dar color a las palabras, es decir, adornarla. En relación con las otras dos materias, cuyo contenido se considera más serio, la retórica resulta ser una disciplina accesoria cuya única función es el ornato. Frente a ella, la dialéctica, que se ocupa de los razonamientos lógicos, tiene un desarrollo independiente (Mortara Garavelli, 1991: 50). La antigua técnica romana del debate (declamatio) pervive en las disputas escolásticas (disputatio), cuya manifestación literaria es el diálogo (p.e.: El diálogo entre el agua y el vino).

Y esta diferente consideración (la dialéctica como disciplina fundamental y la retórica como disciplina complementaria) es la causa del nacimiento de la llamada retórica "restringida", según la expresión acuñada por Gérad Genette. Se trata de un proceso mediante el cual la retórica va perdiendo sus funciones a favor de la dialéctica. Ya en el siglo XV, se adscriben a la dialéctica tanto las técnicas 
354 Revisión crítica de la historia de la retórica desde los postulados de la comunicación

de argumentación como los loci. Por estas mismas fechas, bajo el influjo que el carácter formalista de la oratoria ciceroniana ejerce sobre los humanistas, se potencian los aspectos estilísticos en detrimento de los compositivos. La culminación de este proceso de "reducción" -que algunos llaman de "literaturización"- tiene lugar cuando Pierre de la Ramée (a. Petrus Ramus, 1515-1572) le asigna a la dialéctica la inventio y la dispositio y a la retórica, la elocutio (Mortara Garavelli, 1991: 52). Se consuma así el reparto y despojo de las operaciones retóricas que se venía configurando desde antiguo. La gran influencia de Ramée es el certificado de defunción de la retórica aristotélica, que, de esta forma, queda unida a la poética y reducida a una simple disciplina de ornato. A partir de este momento, la retórica pierde su carácter argumentativo, y al centrarse en los aspectos formales del lenguaje, une su destino a la Literatura, cerrándose así el ciclo iniciado por Gorgias. El resto de su historia se reduce a una sucesión de acartonados manuales escolares.

El cuarto y último proceso (rechazo) lo padece no tanto la retórica (disminuida y literaturizada) como la dialéctica $Y$ tiene lugar a lo largo de la Edad Moderna. La dialéctica solo procura opiniones verosímiles. De ahí que el hombre moderno, en su búsqueda de la verdad, rechace la dialéctica, porque versa sobre lo probable y porque solo proporciona opiniones verosímiles. Este hombre, muy influido por el platonismo, estima que a la verdad solo puede accederse a través de la meditación filosófica (cartesianismo) o de los sentidos (empirismo). Para Descartes todo lo verosímil es falso, porque deriva del triunfo dialéctico de una idea y no del razonamiento filosófico, y para Locke la retórica es el arte de la mentira. A pesar de su oposición ideológica, racionalistas y empiristas tienen idéntica visión de la dialéctica, para ambos es "una pantalla entre el espíritu y la verdad" (Reboul, 1991: 90), porque ambos buscan una verdad sublime, independiente, que nada tiene que ver con las controversias de la dialéctica. En este sentido, como afirma Berrio, "el espíritu cartesiano de la evidencia y el afán empirista de encontrar una definición de la verdad a partir de la experiencia sensible, serán un golpe decisivo, no solo para la retórica, sino también para lo que podía quedar aún del pensamiento basado en la opinión y la verosimilitud" (1983: 42). El positivismo decimonónico y el cientificismo del pasado siglo confirman triunfo de esta tendencia al tiempo que cercioran el repudio de la retórica y la dialéctica. Cuando Victor Hugo, en pleno Romanticismo, proclama "Guerra a la retórica, paz a la sintaxis", lo que está haciendo es incorporar las Letras (el mundo de la palabra) al rechazo que la Ciencia (el mundo de la naturaleza) ya ha consumado.

\section{EL RENACIMIENTO DE UNA TÉCNICA ANTIGUA}

La historia europea de las ideas es una reproducción -y continuación- del desarrollo y enfrentamiento ideológicos llevados a cabo en Grecia. De una parte están los sofistas, y, de otra, Platón y sus discípulos. El triunfo de estos y el ostracismo al que, en consecuencia, quedaron reducidos aquellos, marca una línea de pensamiento que llega hasta el presente. Puede establecerse un vínculo, más 
o menos tenue, más o menos acentuado, entre Platón, el Aristóteles de la Lógica, la Iglesia, el racionalismo, el empirismo, el positivismo y el cientificismo (Berrio, 1983: 45). El nexo común entre todos ellos es la creencia en o la búsqueda de unos valores absolutos, ajenos y superiores al hombre, intangibles para él y cuya existencia solo puede aceptar o certificar, ya sea la Verdad, ya sea la Palabra, ya sea la Ciencia.

En cambio, la concepción de la sofística perdió la batalla al final de la Antigüedad. $Y$ desde entonces ha vivido un extenso letargo, acosada unas veces y acusada otras. Pero siempre postergada en aras de los valores absolutos que el hombre persigue. No obstante, en la segunda mitad del siglo XIX y a lo largo del XX, se observa el florecimiento de ciertas corrientes que, resistiéndose a la impronta científica o "universalista", ponen el acento en el hombre. La aparición de disciplinas relacionadas con la antropología, la sociología o la psicología, de una parte, y la lingüística, la semiótica o la pragmática, de otra, evidencian este rebrote de las ideas de la sofística. Todas ellas se interesan por el hombre, desde una u otra vertiente, si bien todas se relacionan con un tipo de verdad del que no se habían ocupado la filosofía y la ciencia tradicionales. El nihilismo, el expresionismo, el surrealismo, el historicismo o el existencialismo son manifestaciones de esta preocupación y expresan un interés inusual por aspectos del hombre hasta ahora desatendidos. Figuras como Nietzsche, Camus o Wittgenstein jalonan esta curiosidad hacia otros aspectos de lo humano.

El origen de esta nueva tendencia, relacionada con la sofística, hay que ubicarla en el Renacimiento, época en la que todo lo relacionado lo humano recibe una atención inusitada y en la que también -sorprendentemente- se recupera y fortalece la otra corriente, la platónica. La llustración, con su preocupación por "el jardín terrenal", que desemboca en la creación del mito del progreso, y el Romanticismo, con el descubrimiento de los sentimientos y con su búsqueda de lo genuino, van consolidando, a lo largo del tiempo, esta tendencia "humana" que, en el siglo $X X$, se consolida y logra abrir una brecha en el "imperio de la razón analítica". Y en este contexto, en el que junto a la preponderancia de la ciencia figura ya, aunque en mucho menor escala, el interés por lo humano, es en el que hay que ubicar la recuperación de la vieja retórica.

El hecho de que, durante más de dos siglos, se hayan desatendido las antiguas técnicas de argumentación se debe, en palabras de Perelman, a la "negligencia" de los teóricos del conocimiento que no han tenido en cuenta "lo que hay de no apremiante en los argumentos que sirven para una tesis". La argumentación, por naturaleza, se opone a la necesidad y a la evidencia, por ello "no se delibera en los casos en los que la solución es necesaria ni se argumenta contra la evidencia". El terreno de la argumentación es lo probable, "en la medida en que escapa al cálculo" (1994: 30). Este planteamiento es el que permite el retorno de la retórica clásica. En este sentido, puede decirse que en el pasado siglo vuelven a encontrarse las dos posturas griegas (Berrio, 1983: 44). De una parte, "el desarrollo vigoroso de la razón analítica, o sea, la tradición de pensamiento 
356 Revisión crítica de la historia de la retórica desde los postulados de la comunicación

que en la Antigüedad [se relaciona] con la tradición platónica y con la lógica aristotélica", y, de otra, "un interés renovado por las disciplinas del universo de la actuación humana y de la toma de decisiones, las cuales [se relacionan], a su vez, con la sofística y la dialéctica, así como también con la retórica aristotélica". Puede afirmarse, pues, que junto al Aristóteles de la Lógica, relacionada con los valores absolutos, se sienta ahora el Aristóteles de la Retórica, relacionada con los valores relativos.

El artífice de la rehabilitación académica de la retórica clásica es Chaim Perelman cuyo objeto de estudio son los problemas de argumentación del lenguaje jurídico. En 1958 publica un libro que marca el comienzo de una nueva etapa para la retórica: Tratado de la argumentación, que lleva un significativo subtítulo: La nueva retórica. Estos son los dos temas que trata: la argumentación y la retórica. Si bien en realidad es solo uno, pues ambas expresiones se refieren a un mismo concepto. En las primeras líneas de la "Introducción", Perelman afirma que "La publicación de un tratado dedicado a la argumentación y a su vinculación a una antigua tradición, la de la retórica y la dialéctica, constituyen una ruptura con la concepción de la razón y del razonamiento que tuvo su origen en Descartes y que ha marcado con su sello la filosofía occidental durante los tres últimos siglos" (1994: 30). Ya desde el comienzo es consciente del papel rupturista e innovador que presenta su tratado, que "se ocupará -dice- únicamente de los medios discursivos que sirven para obtener la adhesión del auditorio", por ello "examinará la técnica que emplea el lenguaje para persuadir y para convencer" (1994: 39). Y también es consciente de su deuda con los "autores griegos y latinos, quienes estudiaron el arte de persuadir y de convencer, la técnica de la deliberación y de la discusión". Por este motivo presenta su tratado como "la nueva retórica" (1994: 35).

El punto de partida de Perelman es la distinción que establece Aristóteles entre la lógica, de una parte, y la retórica, la dialéctica y la filosofía, de otra (González Bedoya, 1994: 15). Es decir, entre la ciencia de la demostración y las ciencias de lo probable, es decir, de la argumentación. La ciencia de la demostración se basa en la razón teorética, con sus categorías de verdad y evidencia; sus pruebas racionales e irrefutables; su método es la demostración; y su objetivo es la verdad. En cambio, las ciencias de la argumentación se fundamentan en la razón práctica, con sus categorías lo verosímil y lo razonable; sus pruebas probables y preferibles; su método es la argumentación; y su objetivo es lo verosímil, lo plausible, lo probable. La retórica se adscribe a la filosofía, porque, como esta, su objetivo no es demostrar, sino argumentar. Si bien, entre ambas hay una diferencia. La filosofía se dirige a un auditorio universal con la pretensión de convencerlo. En cambio, la retórica, se dirige a un público concreto con el objetivo de persuadirlo. Convencer y persuadir son dos finalidades de la argumentación, pero mientras que la primera no trasciende la esfera mental, la segunda, por el contrario, desemboca en un resultado práctico: ya la adopción de una actitud, ya su puesta en práctica. De este modo, Perelman rescata la dicotomía aristotélica, lo que le permite recuperar la argumentación, en general, y la retórica, en 
particular, y, al mismo tiempo, ubicarlas en un mundo del que nunca debieron haber sido expulsadas.

Este interés académico por las teorías de la argumentación coincide con un fenómeno de gran trascendencia en el mundo occidental: la democratización, ya en el terreno político (los regímenes parlamentarios), ya en el económico (la sociedad de consumo). La retórica dejó de tener sentido en un mundo en el que las libertades civiles fueron suprimidas. Esta técnica para preparar discursos con los que persuadir al auditorio floreció en una sociedad que la necesitaba. Y esta sociedad, por razones políticas, desapareció, primero, con la derrota de las ciudades-estado griegas y, segundo, con la instauración del Imperio romano. Habrá que esperar casi dos milenios para que vuelvan los grandes debates políticos, que es el terreno propicio para el desarrollo de la retórica (Reboul, 1991: 86). La re-instauración de las democracias (formales) en Europa después de la Segunda Guerra Mundial acentuó y consolidó un proceso de democratización que se había iniciado con la Revolución francesa. A la democracia política debe sumársele la democracia cultural, que se instaura en Occidente con el desarrollo de los medios de comunicación de masas (Gonzalez Bedoya, 1994: 18). Y este desarrollo de los medios de comunicación está estrechamente vinculado, a su vez, con la sociedad de consumo, y su portavoz: la publicidad.

La implantación de la sociedad de consumo a partir de la segunda mitad del siglo XX corre paralela, en muchos casos, a la democratización política. El desarrollo tecnológico y el auge económico generan, por su parte, la democratización del consumo y su posterior banalización. La sociedad de consumo supone, por tanto, una extensión del consumo hasta ahora desconocido. Y en este proceso de generalización consumística la publicidad juega un papel fundamental. El discurso político, de ascendencia clásica, y el discurso publicitario, moderno de nacimiento (Rey, 2003), tienen en común que ambos versan lo probable y lo preferible. Y esto es justamente lo que los vincula con retórica clásica: su carácter relativo. Y también su reinserción en la vida cotidiana. Hoy, en una sociedad libre, igual que sucedía en la Grecia democrática, resulta indispensable recurrir al discurso con el fin de persuadir al destinatario para que apoye una opción política o adquiera un producto. En este sentido, son de gran interés las investigaciones realizadas por Peter Simonson sobre retórica y vida cotidiana (2010a) y sobre retórica y política (2010b), publicaciones ambas que han de enmarcarse en la gran corriente norteamericana que en la actualidad se interesa por la retórica, y que vienen a demostrar la importancia que la vieja retórica ha adquirido en las sociedades contemporáneas. Superando la vieja concepción literaturizante, modernamente se ha impuesto una visión de la retórica práctica, cotidiana, utilitarista en el sentido de Tácito, es decir, se ha impuesto la retórica que necesita una sociedad que debe recurrir a la palabra para establecer acuerdos, pactos, consensos, y esto solo se consigue mediante la argumentación que es, en suma, la razón del nacimiento de la retórica.

En la actualidad, la adhesión de los ciudadanos a unos valores no se obtiene 
358 Revisión crítica de la historia de la retórica desde los postulados de la comunicación

mediante la fuerza, como hicieron los tiranos de Siracusa y cuantos les imitaron, tampoco se consigue mediante la coacción de la condena eterna, como hizo la Iglesia, hoy, como en la Grecia libre, el único medio para lograr la adhesión es el discurso, la palabra, pero no vista desde una perspectiva ornamental, sino argumentativa. La retórica vuelve ser, pues, una práctica social que pasa a formar parte de la vida cotidiana, recuperando así su carácter comunicacional. Y como antaño, se emplea para adoptar acuerdos que hagan la vida más favorable. El empleo de las técnicas de argumentación constituye la seña de identidad de una sociedad que, de nuevo, confía en el hombre y le concede la libertad para argumentar y le otorga la capacidad de decidir sobre su destino, aun a riesgo de equivocarse.

Esta es la aportación de la nueva retórica y este es el contexto histórico en el que se desarrolla su renacimiento y su revitalización, un contexto en el que confluyen un proceso económico, que hunde sus raíces en la Revolución industrial, y un proceso político, que se remonta a la Revolución francesa; y que en la actualidad se fusionan cuando el discurso político adopta las formas y los modos de comunicación del publicitario porque los considera más adecuados para sus objetivos.

\section{CONCLUSIONES}

Como conclusión, se puede establecer una correlación entre retórica, democracia y relativismo. El nexo es la comunicación. Primero: la retórica es una técnica surgida para resolver conflictos. Su campo de acción es la comunicación. En él, los individuos se encuentran para resolver sus diferencias y establecer puntos comunes que propicien el bienestar general. Segundo: mientras la retórica se encuentre un terreno favorable, es decir, en una sociedad que la "necesite", en palabras de Tácito, tendrá sentido. Y entonces pasará a formar parte de la vida cotidiana. Así sucedió en las sociedades de la Grecia clásica y la Roma republicana. Y también en las sociedades democráticas y de consumo. En todas ellas ha florecido o florece la libertad. Es un contrasentido hablar de retórica en las sociedades en las que está prohibido el debate, la disputa. Tercero: este poder establecer acuerdos conduce a la desaparición de valores absolutos y a la existencia de otros más flexibles, más relativos. Todo depende de lo que los hombres acuerden. $Y$ cuarto: la vinculación de estas tres cuestiones radica en la comunicación. La retórica es fruto de la comunicación, la democracia es un gran ejercicio de comunicación, y el relativismo es consecuencia directa de la comunicación establecida retóricamente por los hombres en una sociedad libre. Por ello, circunscribir la retórica a los aspectos formales es reducirla, restringirla, condenarla. Porque nace como técnica social de comunicación, es decir, como vehículo para establecer acuerdos en la vida cotidiana. No tiene sentido ceñirla a las cuestiones literarias. Su campo de acción es la vida cotidiana. Y la comu- 
Juan Rey

nicación.

\section{REFERENCIAS BIBLIOGRÁFICAS}

ALBALADEJO, T. (1989): Retórica. Madrid: Síntesis.

ALBERTE, A. (1994): "Actitud de los cristianos ante la retórica durante el periodo tardo latino y medieval". Actas del primer encuentro interdisciplinar sobre retórica, texto y comunicación, vol. I, pp. 137-143.

ARISTÓTELES (1999): Retórica. Madrid: Gredos.

BARTHES, R. (1990): La aventura semiológica. Barcelona: Paidós.

BERRIO, J. (1983): "La teoría de la persuasión. Una visión histórica". En BERRIO, J.: Teoría social de la persuasión. Barcelona: Mitre, pp. 9-54.

DÍAZ TEJERA, A. (1994): "De la ciencia a la técnica. Aristóteles y la retórica posaristotélica". Actas del primer encuentro interdisciplinar sobre retórica, texto y comunicación, vol. I, pp. 1-20.

GARCÍA CASTILLO, P. (1994): "Retórica y filosofía. Porfirio: La gruta de las ninfas". Actas del primer encuentro interdisciplinar sobre retórica, texto y comunicación, vol. I, pp. 79-85.

GENETTE, G. (1972): Figures III. Paris: Seuil, pp. 21-40.

GONZÁLEZ BEDOYA, J. (1994): "Prólogo a la edición española". En PERELMAN, CH. \& OLBRECHTS-TYTECA, L.: Tratado de la argumentación. La nueva retórica. Madrid: Gredos, pp. 7-26.

LAUSBERG, H. (1983): Manual de retórica literaria I. Madrid: Gredos.

MORTARA GARAVELLI, B. (1991): Manual de retórica. Madrid: Cátedra.

MURHPY, J. (ed.) (1988): Sinopsis histórica de la retórica clásica. Madrid: Gredos.

--(1986): La retórica en la Edad Media. Historia de la teoría de la retórica desde san Agustín hasta el Renacimiento. México: Fondo de Cultura Económica.

REBOUL, O. (1991): Introduction à la rhétorique. Paris: PUF.

PERELMAN, CH. \& OLBRECHTS-TYTECA, L. (1994): Tratado de la argumentación. La nueva retórica. Madrid: Gredos.

RITORÉ PONCE, J. (1994): "El debate entre retórica y filosofía y la exégesis neoplatónica de Gorgias y Fedro". Actas del primer encuentro interdisciplinar sobre retórica, texto y comunicación, vol. I, pp. 72-78.

RACIONERO, Q. (1999): “Introducción, traducción y notas”. En ARISTÓTELES: Retórica. Madrid: Gredos, pp. 7-152.

REY, J. (2003 ): "Notas para un análisis del discurso publicitario a la luz de la Retórica 
360 Revisión crítica de la historia de la retórica desde los postulados de la comunicación

aristotélica". Cauce. Revista de Filología y su Didáctica. n² 26, pp. 429-448.

-(2008): "Forma, discurso e ideología en el mensaje publicitario". Ámbitos. Revista Internacional de Comunicación, no 17, pp. 323-341.

ROMÁN, R. (1994): "La seducción del lenguaje. El origen de la retórica". Actas del primer encuentro interdisciplinar sobre retórica, texto y comunicación, vol. I, pp. 39-51.

ROMILLY, J. (2010): Los grandes sofistas de la Atenas de Pericles. Madrid: Gredos.

SIMONSON, P. (2010a): "A cultural sociology of rhetoric: Hugh Duncan's forgotten corpus". En PORROVECCHIO, M.J. (ed.): Current conversations and contemporary challenges. New York: Routledge, pp. 112-131.

-(2010b): "The streets of Laredo. Mercurian rhetoric and the Obama Compaign". Western Journal of Communication. $n^{\circ}$ 74/1, pp. 94-126.

SPANG, K. (2006): Persuasión. Fundamentos de retórica. Pamplona: EUNSA.

\section{Breve semblanza del autor}

Juan Rey es doctor en comunicación (sección Publicidad) y en Filología Hispánica. En la actualidad es Profesor Titular de Universidad en el departamento de Comunicación Audiovisual y Publicidad de la Facultad de Comunicación de la Universidad de Sevilla. Es director del grupo de investigación en Métodos, Análisis y Estrategias de la Comunicación Empresarial e Institucional (MAECEI). Asimismo es director de Questiones Publicitarias. Revista Internacional de Comunicación y Publicidad, y del máster en Dirección de Comunicación Empresarial e Institucional (título propio de la Universidad de Sevilla) que se imparte en la Facultad de Comunicación. Sus líneas de investigación se centran en los aspectos retóricos, redaccionales y simbólicos de la publicidad, sobre los que ha publicado numerosos libros y artículos.

(Recibido el 13-09-2011, aceptado el 07-11-2011). 